\title{
PREVALENCE OF METHICILLIN RESISTANT STAPHYLOCOCCUS AUREUS IN GADCHIROLI (M.S.), INDIA
}

\author{
Jungari, M.J. \\ PGTD of Microbiology, RTMNU, Nagpur (M. S.), India \\ Corresponding author email: yogeshwthere@gmail.com
}

\begin{abstract}
:
Health care associated infections are the main reason for the higher morbidity and mortality rate and the management of all these conditions has been critically compromised by the appearance and rapid spread of antimicrobial resistance among the organisms floating in the hospital. Methicillin resistant Staphylococcus aureus (MRSA) infections have become a major problem worldwide. The problem is not restricted to developed countries. The present study investigated the prevalence rate of MRSA strain in tribal district Gadchiroli. Fifty-three of 72 isolates of Staphylococcus spp. were identified as coagulase positive $S$. aureus. All these isolates were further tested against 12 locally available antibiotics to determine antibiotic susceptibility patterns. The current study revealed a high prevalence rate of methicillin resistant S. aureus strains in tribal district Gadchiroli. It emphasizing the compulsion for local or country-based investigations to characterize and monitor MRSA and to develop strategies that will accelerate MRSA management and control. In our study, Vancomycin, Amikacin, Chloramphenicol and Gentamycin were found to be the most effective antibiotics against the $S$. aureus isolates among the routinely used antibiotics in this region.
\end{abstract}

Keywords: Methicillin, staphylococcus, antibiotics and MRSA.

\section{INTRODUCTION:}

Over the past decades, there has been rise in percentage antibiotic resistant pathogens and strains in different type of infection. The bacterial had well controlled after the discovery of penicillin in 1940 until Staphylococcus aureus stared producing enzyme beta-lactamase, which destroy the penicillin beta-lactam core ring ${ }^{1,2}$. To counter the penicillin resistance there was development of methicillin drug (semi-synthetic penicillin). Infection of $\mathrm{S}$. aureus was well control by methicillin antibiotic in that period ${ }^{3}$. However, within 2 year, the first methicillin-resistant $S$. aureus (MRSA) strains were identified ${ }^{4}$, followed by a report on the first MRSA outbreak in $1963^{5}$. Since then, MRSA has become the recorded as prevalent pathogen causing hospital infection throughout the world, and MRSA incidence is still increasing in many countries ${ }^{6,7}$. Methicillin resistant Staphylococcus aureus (MRSA) emerged in the 1980 s as a major clinical and epidemiologic problem in hospitals. Presently, hospitals of all sizes are facing the MRSA problem. Recommendations for the management or control of the spread of MRSA have been made available 8,9 . Nasal carriage of S. aureus or MRSA has been suggested as risk factor for the developments of infections.

Treatment results with vancomycin, the gold standard antibiotic against MRSA, is less than ideal in view of suboptimal efficacy, lack of an oral formulation, increased toxicity, and higher costs compared to beta-lactam antibiotics. Reports of vancomycin intermediately susceptible $S$. aureus (VISA), first isolated in Japan in 199710, and vancomycin-resistant S. aureus (VRSA) caused widespread alarm among physicians as it was feared that we are entering in pre-antibiotic era again. MRSA evolves to VRSA by acquiring the plasmidborne vanA gene from vancomycin resistant Enterococci (VRE). Both VRSA and VISA represent evolutionary steps taken by $S$. aureus to adapt to the nosocomial milieu of increased glycopeptide use. Although nosocomial infection are significantly important for morbidity and mortality both in developed and developing countries.

Vidarbha region of Maharashtra state is a central part of our country including tribal district Gadchiroli. Limited reports were available on development of methicillin and vancomycin resistant Staphylococcus aureus form this part of India. The purpose of present study is to determine the prevalence rate of methicillin resistant $\mathrm{S}$. aureus in Gadchiroli district of Vidarbha region.

\section{METHOD AND MATERIAL:}

\subsection{Sample collection and S.aureus identification}

From Government district hospitals, Gadchiroli the total 100 clinical samples were collected from different source and 72 samples were positive for $S$. aureus. The quality control and rejection criterion of 
the specimen was followed ${ }^{11}$. The $S$. aureus isolates were identified on the basis of morphological characteristics, microscopic examination of stained preparation and various biochemical tests such as catalase reaction, coagulase production (slide test and tube test), voges-proskauer (VP).

\subsection{Antimicrobial susceptibility testing}

In vitro antimicrobial susceptibility tests were performed on Mueller-Hinton agar by two methods: The disk diffusion method as described by the Clinical and Laboratory Standards Institute (CLSI) standards by using antimicrobial agents Methicillin (MET), Vancomycin (V), Amikacin (AK), Tetracyclin (TE) Erythromycin (E ), Gentamycin (GN ), Oxacillin(OX), Chloramphenicol(C), Penicillin (P), Tobramycin (TB), Norfloxacin (NX), Nitrofurantoin (NF). MIC determination for oxacillin and vancomycin were done by E-test method as per CLSI standards ${ }^{12}$.

\section{RESULT \& DISCUSSION}

\subsection{Specimen analysis}

From Government district hospitals, Gadchiroli the total 100 clinical samples were collected from different source and 72 samples were positive for $S$. aureus. Out of these 53 clinical samples were positive for coagulase test (Table 1). Out of total, 30 $(56.60 \%)$ and 23 (43.40\%) of Staphylococcus aureus isolates were isolated from males and females, respectively.

\section{Overall resistant patterns of $S$. aureus}

A total of 53 viable strains of coagulase positive $S$. aureus from Gadchiroli region were tested for antimicrobial susceptibility by disc diffusion. The antibiotic susceptibility test by disc diffusion was done on each isolate by using 12 antibiotics; Oxacillin (OX), Amikacin (AK), Tetracycline (TE), Erythromycin (E), Gentamycin (GN), Methicillin (MET), Chloramphenicol (C), Penicillin (P), Tobramycin (TB), Norfloxacin (NX), Nitrofurantoin (NF) and Vancomycin (V).

The overall resistance pattern of each antibiotic tested was as follows; oxacillin 32 (60.37\%), Amikacin 12 (22.64\%), Tetracycline 22 (41.51\%), Erythromycin 38(71.70\%), Gentamycin 20 (37.74\%), Methicillin 32 (60.38\%), Chloramphenicol 11 (20.75\%), Penicillin $43(81.31 \%)$, Tobramycin 27 (50.94\%), Norfloxacin 25 (47.16\%), Nitrofurantoin 27 (50.94\%) and Vancomycin 09 (16.98\%) (Table 2) [Figure 2]. Most of the tested antibiotics had shown higher resistance towards MRSA strains except amikacin and chloramphenicol. So, these two antibiotics are good choice for the treatment of Staphylococcus aureus infection.

MRSA is recognized as a problem worldwide. It has appeared as a major hospital pathogen in various hospitals in Europe and America in 80's and continued to be so in 90's. The prevalence of MRSA has widely diverse from hospital to hospital in various countries. S. aureus infections acquired about $40 \%$, in large US hospitals are methicillinresistant. . In many American and European hospitals, the percentage of MRSA has ranged from $29 \%$ to $35 \%$ of all clinical isolates ${ }^{13}$. In India prevalence of MRSA in hospitals varies considerably from one region to another and among hospitals but the data on the prevalence of MRSA strains in most of the region especially tribal region in Indian are limited. In several Indian hospitals prevalence of MRSA varies from $22 \%$ to $68 \%$, as per current Indian Network for Surveillance of Antimicrobial Resistance (INSAR) group's report $2013^{14}$. Prevalence of MRSA has increased rapidly since 1993 at tertiary care centre from $12 \%$ in 1992 to $80.89 \%$ in 1999 . The MRSA isolates showed resistance to several other therapeutic drugs. Incidence of MRSA was as low as $6.9 \%$ in 1988 in India and reached to $24 \% \& 32.8 \%$ in Vellore \& Lucknow reported in 199415,16. Overall prevalence remained in the same range in Mumbai, Delhi \& Bangalore in 1996 and Rohtak 17 \& Manglore 18 in 1999. However, the situation appeared to be more alarming in Tata hospital in Mumbai ${ }^{19}$ where, it reached to $87 \%$ in 1995 and tapered to $64 \%$ in 1996. In 2001 Vidhani et. al. found 51.6\% MRSA prevalence in New Delhi 20. The INSAR group ${ }^{21}$, India reported MRSA prevalence was $42 \%$ in 2008 and $40 \%$ in 2009. According to Khan, et. al., study prevalence of MRSA 32\% in 201122. In current study the incidence rate of methicillin resistance among 53 coagulase positive $S$. aureus isolates on disc diffusion was found $60.37 \%$ which is higher than the previous study.

\section{CONCLUSION:}

The current study revealed a high prevalence rate of methicillin resistant $\mathrm{S}$. aureus strains in tribal district Gadchiroli., It emphasizing the compulsion for local or country-based investigations to characterize and monitor MRSA and to develop strategies that will accelerate MRSA management and control. In our study, Vancomycin, Amikacin, Chloramphenicol and Gentamycin were found to be the most effective antibiotics against the $S$. aureus isolates among the routinely used antibiotics in this region. It might be a good choice for the treatment of methicillin resistant $S$. aureus infections. The increasing trend of antimicrobial resistance was 
observed in present study. Further molecular studies are required to identify resistance-conferring genes.

\section{REFERANCE :}

Khan SA, Feroz F, Noor R. Study of extended spectrum $\beta$-lactamase producing bacteria from urinary tract infection in Dhaka city, Bangladesh. Tzu Chi Med J. 2013;25: 39-42.

Peacock S. Staphylococcus aureus. In: Gillespie S, Hawkey P, editors. Principle and practice of clinical bacteriology. 2nd ed. England: John Wiley and Sons Ltd; 2006. p. 620.

Lowy F. Staphylococcal infections. In: Fauci A, Braunwarld E, Kasper D, Hauser S, Longo D, Jameson J, editors. Harrison's principles of internal medicine. 16th ed. New York: MacGraw-Hill Companies; 2005. p. 2958.

Jevons, M. "Celbenin"-resistant staphylococci. Br. Med. J., 1961;1:124-5.

Stewart, GT., Coles,HM., Nixon, HH. and Holt, RJ. "Penbritin": AnOral Penicillin with Broadspectrum Activity. Br. Med. J. 1961 Jul 22; 2(5246):200-06.

Voss, A., Milatovic, D., Wallrauch-Schwarz, C., Rosdahl, VT. and Braveny, I. Methicillinresistant Staphylococcus aureus in Europe. Eur. J. Clin. Microbiol Infect Dis. 1994; 13:5055.

Tiemersma,EW., Bronzwar, SL., Lyytikainen, O., Degener, JE., Schrijnemakers, P., Bruinsma, N., Monen, J., Witte, W. and Grundman, H. European Antimicrobial Resistance Surveillance System Participants Methicillinresistant Staphylococcus aureus in Europe, 1999-2002. Emerg Infect Dis. 2004; 10:1627634.

Boyce, JM.1991.Should we vigorously try to contain and control methicillin-resistant Staphylococcous aureus? Infect. Control Hosp.Epidemiol.12: 46-54.

Boyce, J. M. 1995. Strategies for controlling Methicillin resistant Staphylococcus aureus in hospitals . J. Chemother. 7 (Suppl.3): 81-85.

Root length (cm)

Table 1: Coagulase positive \& negative with number of samples of $S$. aureus in Gadchiroli

\begin{tabular}{llll}
\hline Sample & CoPSA & CoNSA & Total \\
\hline Pus & 26 & 04 & 30 \\
Sputum & 08 & 06 & 14 \\
Burned Wound & 19 & 09 & 28 \\
\hline Total & 53 & 19 & 72 \\
\hline
\end{tabular}

Hanaki, H., Ino, T. and Tenover, FC. Methicillin resistant $S$ aureus clinical strain with reduced vancomycin susceptibility. J Antimicrob Chemother. 1997;40:135-8.

Looney, WJ. Small colony varients of Staphylococcus aureus. Br. J. Biomed. Sci.,2000; 57:317-22.

Proctor, RA., and Peters, G. Small colony varients in Staphylococcus infection: Diagnostic and Therapeutic implication. Clin. Infect. Dis.1998; 27:419-23

RedBook. Report of the Committee on Infectious Diseases, 26th ed. Staphylococcal Infections., 2003; 561-73.

Indian Network for Surveillance of Antimicrobial Resistance (INSAR) group, India Methicillin resistant Staphylococcus aureus (MRSA) in India:Prevalence\&susceptibility pattern. Indian J. Med. Res., 2013;137: 363-69.

Pulimodd, TB., Lalitha MK., Jesudason, MV., Pandian R., Selwyan J. and John, TJ. Spectrum of antimicrobial resistance among MRSA in a tertiary care centre in India, India J. Med. Res., 1996; 103:212-5.

Mathur, SK., Singal, S., Prasad, KN., Kishore J. and Ayyagiri A. Prevalence of MRSA in tertiary care hospital, Indian J. Medical Micro., 1994;12:96101.

Choudhary, U. and Anupama.Prevalence of methicillin resistance in $S$. aureus. Indian $\mathrm{J}$. Medical Micro., 1999; 17:154-55.

Balgia, S., Shenoy, S., Vidyalaxmi, K. and Dhanshree, B. Netilmicin resistance in $S$. aureus. Nat. Med. J. India., 1999; 12:192-92.

Mehta, A., Rodrigues, C., Kumar, et al.A pilot programme of MRSA surveillance in India. J. Postgraduate, Med., 1996;42:1-3.

Vidhani, S., Mehndiratta, PL. and Mathur, MD.Study of methicillin resistant S. aureus (MRSA)isolates from high risk patients.Indian Journal ofMedical Microbiology., 2001; 29:1316.

Khan, F., Shukla, I., and Rivizi, M. The role of nonbeta-lactum antimicrobial and screening for Vancomycin resistance in MRSA. Malaysian J. Microbiol, 201; 7:66-70. 
Table 2: Over all distribution of antimicrobial susceptibility of S. aureus on disc diffusion in Gadchiroli (Total No. 53))

\begin{tabular}{clllll}
\hline \multirow{2}{*}{ Sr. No. } & Name of Antibiotic & \multicolumn{2}{l}{ Resistant } & \multicolumn{2}{l}{ Sensitive } \\
\cline { 3 - 6 } & & No. & $\%$ & No. & $\%$ \\
\hline 1. & Vancomycin (V) & 09 & 16.98 & 44 & 83.02 \\
2. & Oxacillin (Ox) & 32 & 60.37 & 21 & 39.62 \\
3. & Amikacin (Ak) & 12 & 22.64 & 41 & 77.36 \\
4. & Tetracycline (Te) & 22 & 41.51 & 31 & 58.49 \\
5. & Erythromycin (E) & 38 & 71.70 & 15 & 28.30 \\
6. & Gentamycin (GN) & 20 & 37.74 & 33 & 62.26 \\
7. & Methicillin (MET) & 32 & 60.38 & 21 & 39.62 \\
8. & Chloramphenicol (C) & 11 & 20.75 & 42 & 79.24 \\
9. & Penicillin (P) & 43 & 81.13 & 10 & 18.87 \\
10. & Tobramycin (TB) & 27 & 50.94 & 26 & 49.06 \\
11. & Norfloxacin (NX) & 25 & 47.16 & 28 & 52.83 \\
12. & Nitrofurantoin (NF) & 27 & 50.94 & 26 & 49.06 \\
\hline
\end{tabular}

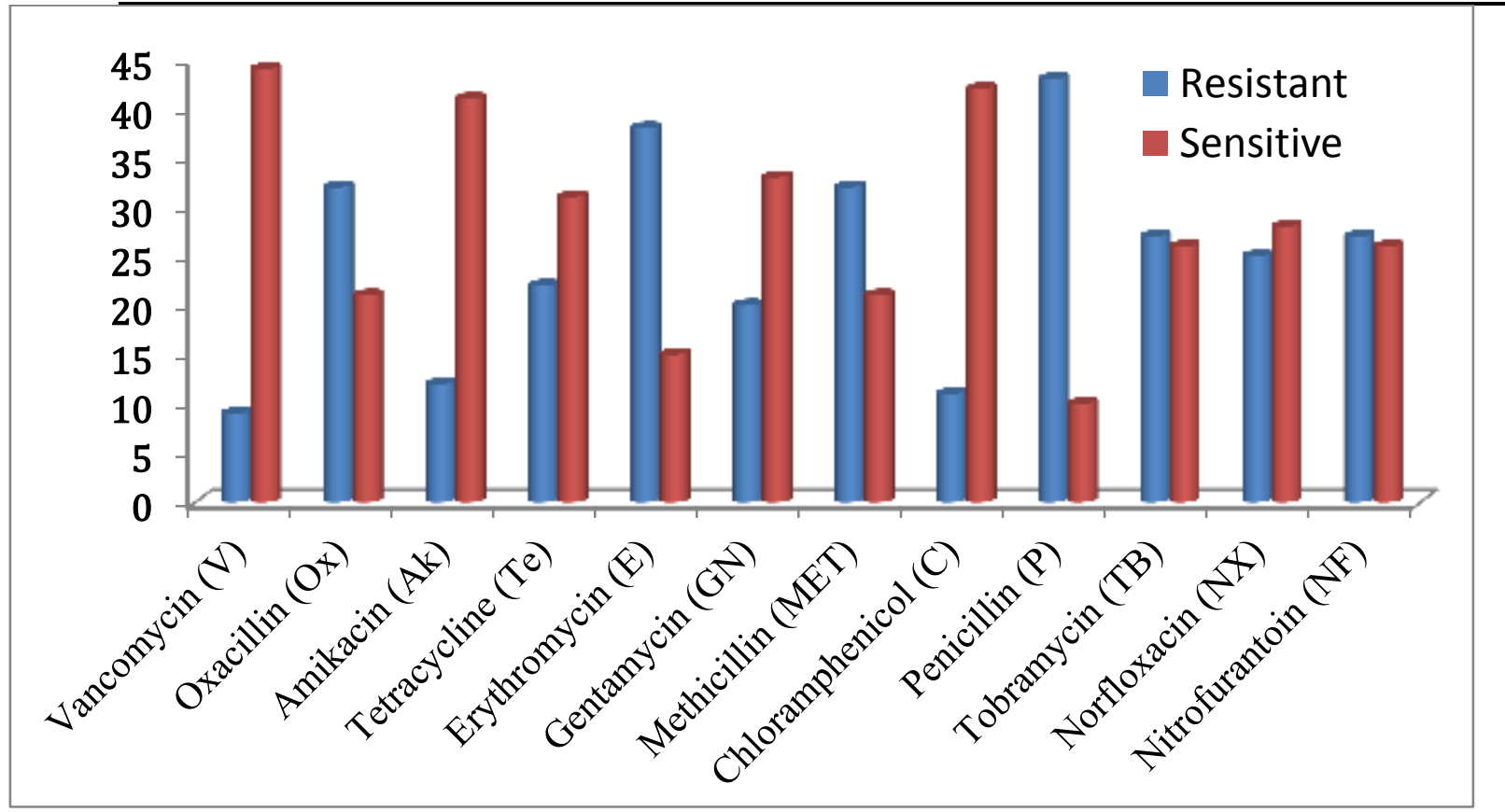

Figure 3 Overall distribution of antimicrobial susceptibility of $S$. aureus on disc diffusion in Gadchiroli 